\title{
The Effect of Lipids on Citric Acid Production by an Aspergillus niger Mutant
}

\author{
By NANCY F. MILLIS, B. HELEN TRUMPY AND BRENDA M. PALMER \\ School of Bacteriology, University of Melbourne, Australia
}

(Received 12 June 1962)

\begin{abstract}
SUMMARY
A mutant strain, 72-44, of Aspergillus niger was selected after ultraviolet irradiation of the spores of $A$. niger strain 72-4. This mutant was capable of giving high yields of citric acid in shaken flask fermentations. A study was made of the effect of various lipids on the yield of citric acid produced by $A$. niger strain 72-44. Fatty acids with less than 15 carbon atoms inhibited growth and no citric acid was produced. Natural oils with a high content of unsaturated fatty acids and oleic acid itself, when added at $2 \%(\mathrm{v} / \mathrm{v})$ to suitable fermentation media, increased the yield of citric acid by about $20 \%$. Lipids which improved the yield of citric acid had no effect on the dry weight of mycelium. The possible mode of action of effective lipids is discussed. It is suggested that unsaturated lipids act as alternative hydrogen acceptors to oxygen during the fermentation and thus improve the yield of citric acid.
\end{abstract}

\section{INTRODUCTION}

The problems associated with citric acid production by fermentation have been reviewed by Foster (1949), Johnson (1954) and Perlman \& Sih (1960). In fermentations with Aspergillus niger, the amount of growth must be small and the medium must contain only very small concentrations of trace metals. These conditions present a serious problem when attempting to carry out this fermentation on an industrial scale. A major difficulty experienced by all workers is associated with inconsistencies in yield. In attempts to solve these problems, strains tolerant of trace metals have been selected (Bernhauer, 1929; Doelger \& Prescott, 1934; Bernhauer, Knobloch \& Iglauer, 1941), or substances to inhibit growth have been added to the medium. Gardner, James \& Rubbo (1956) used X-rays and ultraviolet irradiation to produce mutants with a higher tolerance of trace metals. Perlman (1943), Gerhardt, Dorrell \& Baldwin (1946), Bernhauer, Rauch \& Gross (1949) and Martin \& Waters (1952) used potassium ferrocyanide to decrease the trace metal content of beet molasses media to inhibit growth and increase the yield of citric acid. Moyer (1953) found that methanol, ethanol and isopropanol decreased growth and increased citric acid production from cane and beet molasses media. The present paper describes the selection of a potentially high-yielding mutant of $A$. niger strain 72-4 and the effect on the yield of citric acid of adding various lipids to the fermentation medium.

\section{METHODS}

Organisms. The parent culture was Aspergillus niger Wisconsin strain 72-4 ATCC 11414 (Perlman, Kita \& Peterson, 1946). The mutant used in the present work, strain 72-44, was selected after ultraviolet (u.v.) irradiation of the parent 
culture. Stock cultures were maintained as freeze-dried suspensions of spores in ampoules.

Media for fermentations (Table 1). Four different media were used for shaken flask fermentations, two for the screening mutants after u.v.-irradiation and two for testing the effect of lipids on yield of citric acid. The media used for testing lipids were modified from those reported by Shu \& Johnson $(1947,1948 a, b)$. All media were initially at $\mathrm{pH} 3$; medium was dispensed in $50 \mathrm{ml}$. portions in $500 \mathrm{ml}$. conical flasks and autoclaved at $116^{\circ}$ for $10 \mathrm{~min}$.

Table 1. Media used in shaken-flask citric acid fermentations by Aspergillus niger mutant 72-44

\begin{tabular}{|c|c|c|c|c|}
\hline \multirow{3}{*}{$\begin{array}{c}\text { Media } \\
\text { constituents }\end{array}$} & \multicolumn{2}{|c|}{ Mutant screening } & \multirow{2}{*}{\multicolumn{2}{|c|}{ Lipid testing }} \\
\hline & \multirow{2}{*}{$\begin{array}{l}\text { Low trace } \\
\text { metals }\end{array}$} & \multirow{2}{*}{$\begin{array}{l}\text { High trace } \\
\text { metals }\end{array}$} & & \\
\hline & & & Medium A & Medium B \\
\hline & \multicolumn{2}{|c|}{ (g./1.) } & \multicolumn{2}{|c|}{ (g. $/ 1)}$. \\
\hline Sucrose & $140 \cdot 0$ & $140 \cdot 0$ & $140 \cdot 0$ & $140 \cdot 0$ \\
\hline $\mathrm{KH}_{2} \mathrm{PO}_{4}$ & $1 \cdot 00$ & 1.00 & $1 \cdot 00$ & $\mathbf{0} \cdot 30$ \\
\hline $\mathrm{MgSO}_{4} \cdot 7 \mathrm{H}_{2} \mathrm{O}$ & 0.25 & 0.25 & $0 \cdot 25$ & $0 \cdot 10$ \\
\hline \multirow[t]{2}{*}{$\mathrm{NH}_{4} \mathrm{NO}_{3}$} & $1 \cdot 87$ & $1 \cdot 87$ & 1.87 & $1 \cdot 40$ \\
\hline & \multicolumn{2}{|c|}{ (mg./l.) } & \multicolumn{2}{|c|}{ (mg./l.) } \\
\hline $\mathrm{Fe}^{++}$ & $3 \cdot 0$ & $16 \cdot 0$ & $2 \cdot 0$ & $\mathbf{2 \cdot 0}$ \\
\hline $\mathrm{Cu}^{++}$ & $0 \cdot 3$ & $10 \cdot 0$ & $\mathbf{0 . 3}$ & $0 \cdot 3$ \\
\hline $\mathbf{Z n}^{++}$ & $0 \cdot 1$ & $\mathbf{2 \cdot 0}$ & $0 \cdot 1$ & $0 \cdot 1$ \\
\hline
\end{tabular}

The sucrose was A1 grade commercial cane sugar (Colonial Sugar Refineries, Australia). A 14\% (w/v) solution was passed through a cation exchange resin Zeocarb 215 (Permutit Co.) in the $\mathrm{H}^{+}$form, and the effluent was tested for residual trace metals. It was found to contain (mg./l.): $\mathrm{Fe}^{++}, 0 \cdot 1 ; \mathrm{Cu}^{++}, 0.05 ; \mathrm{Zn}^{++}, 0.05$. The final concentrations of trace metals are listed in Table 1. A.R. grade chemicals were used for all media and no attempt was made to purify them further. Pyrex glassware was used to handle media and solutions of defined trace metal content and was cleaned in the usual way, washed in $10 \%(\mathrm{v} / \mathrm{v})$ solution of redistilled concentrated $\mathrm{HNO}_{3}$, and then rinsed three times with glass-distilled water.

In most cases lipids were added to media before autoclaving. To avoid oxidation, some of the highly unsaturated lipids (e.g. linseed oil, tung oil, linolenic and linoleic acids) were added to the sterile medium just before inoculation with spores.

Conditions of cultivation. All cultures were grown at $30^{\circ}$. All fermentations were carried out in shaken flasks. The shaker was housed in a warm room at $30^{\circ}$ and was rotated at $210 \mathrm{rev} . / \mathrm{min}$. with a $2 \mathrm{in}$. amplitude throw. The table of the shaker had clips to hold $500 \mathrm{ml}$. conical flasks which were tilted at $15^{\circ}$ to the horizontal to improve mixing. The sulphite value of these flasks, containing $50 \mathrm{ml}$. of solution, was $\mathbf{0 . 6}$ as determined by the method of Cooper, Fernstrom \& Miller (1944).

Inoculum preparation. A stock freeze-dried culture was transferred to a beer wort agar slope. When sporing vigorously, the organism was subcultured to 20 similar slopes. When these were sporing, they were stored at $4^{\circ}$ until required. The spores were then suspended in a $1 / 10,000(\mathrm{w} / \mathrm{v})$ sterile solution of Soaxit (sodium dioctyl- 
sulphosuccinate; W. Hermon Slade \& Co., Homebush, New South Wales, Australia) and spread over the surface of beer wort agar in an 8 in. Petri dish. To achieve good sporulation it was necessary to raise the lid of the Petri dish about $0.5 \mathrm{~cm}$. The spores from the plate were harvested in sterile Soaxit, counted in a haemocytometer and, routinely, between $7 \times 10^{7}$ and $2 \times 10^{8}$ spores were used to inoculate $50 \mathrm{ml}$. of medium in shaken flasks.

Estimation of citric acid. Routinely, the yield of citric acid was measured by titrating a $2 \mathrm{ml}$. sample of culture fluid against $0.25 \mathrm{~N}-\mathrm{NaOH}$ (phenolphthalein as indicator), and expressed as g. anhydrous citric acid/100 ml. of culture fluid. To determine whether the titratable acidity was due to citric acid alone, spot tests for oxalic acid were made according to Feigl (1960), citric acid was determined colorimetrically according to Marier \& Boulet (1958) and chromatograms of the culture fluids were run with two different solvent systems, butanol + acetic + water (Smith, 1961) and butanol + formic + sodium formate + water (R. S. D. Read \& N. F. Millis, personal communication.)

Estimation of sugar. Sugar was estimated before and after fermentation using Schaffer \& Somogyi's reagent 50 (1933). For the initial sugar determination, the sucrose was inverted by heating a $1 \mathrm{ml}$. sample at $100^{\circ}$ in $5 \mathrm{ml}$. of $0 \cdot 1 \mathrm{~N}-\mathrm{H}_{2} \mathrm{SO}_{4}$ for $10 \mathrm{~min}$. Acid inversion was not necessary for residual sugar determinations.

Estimation of mould growth. The amount of mould growth was estimated by determining the dry weight of mycelium formed. The contents of a shaken flask were transferred to a weighed Whatman paper No. 541, washed three times with water and the mycelium dried at $60^{\circ}$ for $24 \mathrm{hr}$. before weighing. When the fermentation was carried out in the presence of lipid, free lipid was removed by thoroughly washing the water-washed mycelium with ethanol before drying.

Estimation of oil utilization. To extract the oil after fermentation the mycelium was removed by filtration, washed with water and the filtrate and washings combined. The volume was reduced to one-tenth by vacuum distillation. The concentrate was mixed with 10 vol. ethanol and held overnight at $4^{\circ}$. The polysaccharide precipitate which formed was removed by centrifugation and washed with ethanol. The supernatant fluid and the ethanol washings were combined and the ethanol distilled off. The lipid was then extracted from the aqueous residue with ether. The removal of the polysaccharide was necessary to avoid the formation of emulsions at the ether water interface which occurred when ether extraction was attempted directly on the culture fluid.

The mycelium was dried at $60^{\circ}$ for $24 \mathrm{hr}$., ground to a fine powder and lipid extracted with ether in a Soxhlet. The ether was distilled from both extracts and the residue weighed after drying over phosphorus pentoxide.

Estimation of iodine value. The iodine value of peanut oil samples was measured by Hanus's method as described in Official Methods (1955).

Estimation of peroxide value. The peroxide value of peanut oil samples was measured by the iodometric method of Jacobs (1958).

Saponification. Maize oil was separated into a saponifiable and a non-saponifiable fraction by refluxing with ethanolic $\mathrm{KOH}$ as described by Hilditch (1956). 


\section{RESULTS}

The results reported here are the averages of duplicate fermentations. The divergence between the yields of citric acid in duplicate fermentations was not more than $0.7 \mathrm{~g} . / 100 \mathrm{ml}$.

\section{Selection of mutant 72-44 of Aspergillus niger}

The spores of the parent strain Aspergillus niger 72-4 were harvested from beer wort, filtered to remove clumps, counted in a haemocytometer and standardized at 1-2 $\times 10^{6}$ spores $/ \mathrm{ml}$. One $\mathrm{ml}$. of spore suspension was placed in a $4 \mathrm{in}$. Petri dish on a rotating table $12 \mathrm{~cm}$. below a u.v. lamp (Sterilamp, $2537 \AA$, Westinghouse) for $10 \mathrm{~min}$. Single spores were then spotted out on paper as described by James, Rubbo \& Gardner (1956), except that the paper was soaked for $30 \mathrm{~min}$. in a medium containing (g./l.): 140.0, cane sugar (Al grade commercial); $1 \cdot 00, \mathrm{~K}_{2} \mathrm{HPO}_{4} ; 0 \cdot 25, \mathrm{MgSO}_{4}$. $7 \mathrm{H}_{2} \mathrm{O} ; 1 \cdot 87, \mathrm{NH}_{4} \mathrm{NO}_{3} ;$ (mg./l.) $2 \cdot 0, \mathrm{Fe}^{++} ; 2 \cdot 0, \mathrm{Cu}^{++} ; 1 \cdot 0, \mathrm{Zn}^{++}$; (ml./l.) 100 , of $0.5 \%$ $(\mathrm{w} / \mathrm{v})$ bromcresol green in ethanol. This medium was selected in place of molasses used by James et al., since the zones of acid production were more clearly defined and the concentrations of trace metals more accurately known. About 40,000 colonies which developed on paper from irradiated spores were inspected; of these 120 were selected as potentially better producers of citric acid than the parent. These selected colonies were grown on beer wort agar slopes and the spores tested for the yield of citric acid in shaken-flask fermentations in two media, one with a high-trace metal content and the other with a lower-trace metal content (Table 1). Mutants which yielded well in both media were tested twice more and when they behaved consistently they were retained as stock cultures. Finally, mutant 72-44 was selected as the most promising and used for all work reported in this paper.

Table 2. Yield of citric acid by two strains of Aspergillus niger at 7 days

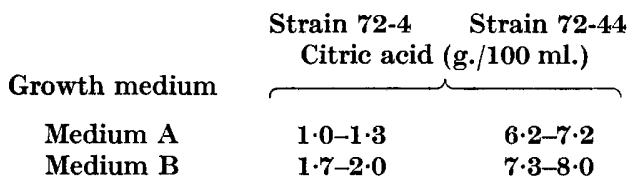

A comparison of the yields obtained with strains 72-44 and 72-4 when grown in media $A$ and $B$ are shown in Table 2. The mutant 72-44 gave about $5 \mathrm{~g}$. more citric acid/100 ml. than did the parent strain. The superiority in yield with the mutant was not as marked when both strains were grown in the presence of peanut oil. Details of the conditions of fermentation which lead to high yields of citric acid with mutant 72-44 will be the subject of another paper.

\section{Number of spores needed in the inoculum}

Early in the study of conditions necessary for the accumulation of citric acid in shaken flasks, considerable variability was experienced under conditions which were apparently identical. Some of this variability was traced to the number of spores used in the inoculum. Fig. 1 shows the yield of citric acid from Medium A when the spores in the inoculum were varied, in two separate experiments, from $1 \times 10^{6}$ to $8 \times 10^{8} / 50 \mathrm{ml}$. of medium. Fig. 1 shows that the yield was best when the inoculum 
size was between $7 \times 10^{7}$ and $2 \times 10^{8}$ spores $/ 50 \mathrm{ml}$. medium. Subsequently, it was found that the yield of acid was always poor when inadequate numbers of spores were used or when the germination of adequate numbers of spores was inhibited.

\section{Effect of the addition of lipids on the citric acid yield}

Following an observation that peanut oil increased the yield of citric acid in aerated and stirred fermentations, a systematic investigation was made in shaken flasks of the effect of various lipids on the yield of citric acid. In any series of fermentations containing test lipids, controls were included with no lipid added and with $2 \%(\mathrm{v} / \mathrm{v})$ peanut oil present. Generally the test lipid was added to medium A, but medium $\mathbf{B}$ was used for some tests, and the yields of citric acid were determined at 7 days.

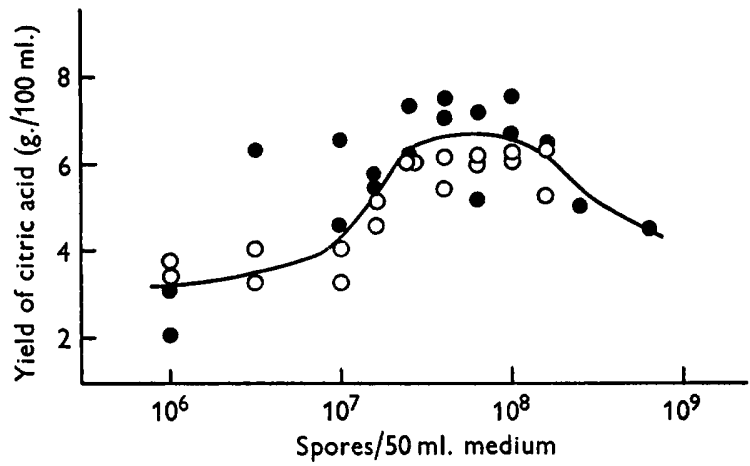

Fig. 1. The effect of the number of spores of Aspergillus niger 72-44 in the inoculum on the yield of citric acid in shaken culture. $O=$ experiment $1 ; 0=$ experiment 2 .

Table 3. Lipids which inhibited growth of Aspergillus niger mutant 72-44 at 7 days $\begin{array}{ccc}\text { No } & \text { Peanut oil } \\ \text { addition } & \text { Lipid } \quad \begin{array}{c}2 \% \\ \text {, v } / \mathbf{v}\end{array}\end{array}$
Lipid added

Natural animal oil : mutton bird

Saturated fatty acids: acetic (2)*, propionic (3), butyric (4), valeric, isovaleric, levulenic (5), phenyl acetic (8), capric (10), undecylic (11), phenyl undecanoic (17)

Unsaturated fatty acids : 2,3-nonenoic (9), 2,3-decenoic (10), 10-undecenoic (11),

2,3-dodecenoic (12), 2,3-tridecenoic (13) Glyceride : tributyrin

\begin{tabular}{|c|c|c|c|}
\hline & $\begin{array}{c}\text { No } \\
\text { addition }\end{array}$ & Lipid & $\begin{array}{c}\text { Peanut oil } \\
2 \%, v / v\end{array}$ \\
\hline Amount & \multicolumn{3}{|c|}{ Citric acid (g./100 ml.) } \\
\hline $\mathbf{2} \cdot \mathbf{0}$ & . & No growth & . \\
\hline $0.05-1.0$ & $5 \cdot 0-8 \cdot 4$ & No growth & $8 \cdot 4-10 \cdot 4$ \\
\hline $0 \cdot 05-1 \cdot 0$ & $4 \cdot 5-8 \cdot 4$ & No growth & $6 \cdot 5-10 \cdot 4$ \\
\hline $\mathbf{2} \cdot 0$ & $5 \cdot 1$ & No growth & $8 \cdot 0$ \\
\hline
\end{tabular}

* Figures in parentheses refer to the number of carbon atoms in the preceding fatty acid.

It was found that some lipids either inhibited spore germination completely or allowed very little growth of the mould, and no citric acid was formed at 7 days. These lipids are listed in Table 3. The figures in parentheses indicate the number of carbon atoms in the preceding fatty acid. Saturated and unsaturated straight-chain 
fatty acids containing from 2 to $\mathbf{1 3}$ carbon atoms were inhibitory to growth. Some lipids allowed normal growth of the mould but gave no improvement in the yield of citric acid. These are listed in Table 4. The figures in parentheses indicate the number of carbon atoms in the preceding fatty acid. Other lipids, listed in Table 5, allowed growth of the mould with increased yields of citric acid.

Table 4. Lipids allowing growth but not increasing citric acid yield by Aspergillus niger mutant 72-44 at 7 days

\begin{tabular}{|c|c|c|c|c|}
\hline & & $\begin{array}{c}\text { No } \\
\text { addition }\end{array}$ & Lipid & $\begin{array}{l}\text { Peanut oil } \\
(2 \%, v / v)\end{array}$ \\
\hline Lipid added & $\begin{array}{l}\text { Amount } \\
(\%, v / v)\end{array}$ & \multicolumn{3}{|c|}{ Citric acid (g./100 ml.) } \\
\hline $\begin{array}{l}\text { Natural vegetable oils: } \\
\text { High \% saturated fatty acid: coconut } \\
\text { High \% unsaturated fatty acids : safflower, } \\
\text { tobacco }\end{array}$ & $\begin{array}{l}2 \cdot 0-10 \cdot 0 \\
0 \cdot 5-1 \cdot 0\end{array}$ & $\begin{array}{l}5 \cdot 0 \\
5 \cdot 0-6 \cdot 5\end{array}$ & $\begin{array}{l}5 \cdot 0 \\
6 \cdot 0-6 \cdot 5\end{array}$ & $\begin{array}{l}8 \cdot 1 \\
8 \cdot 2\end{array}$ \\
\hline Natural animal oil: cod liver & $2 \cdot 0-10 \cdot 0$ & $\mathbf{5 \cdot 2}$ & $2 \cdot 6-5 \cdot 2$ & . \\
\hline $\begin{array}{l}\text { Natural mineral oils: liquid paraffin, light } \\
\text { lubricating, heavy lubricating }\end{array}$ & $2 \cdot 0-10 \cdot 0$ & $6 \cdot 0$ & $2 \cdot 0-6 \cdot 5$ & $9 \cdot 5$ \\
\hline $\begin{array}{l}\text { Saturated fatty acids: tridecylic }(13) * \text {, myristic } \\
\text { (14), pentadecylic (15), palmitic (16), } \\
\text { chaulmoogric (18), arachidic }(20)\end{array}$ & $\begin{array}{r}(0 \cdot 05-0.5 \\
\%, w / v)\end{array}$ & $4 \cdot 4-8 \cdot 4$ & $3 \cdot 0-6 \cdot 2$ & $6 \cdot 5-10 \cdot 4$ \\
\hline Stearic, $12 \mathrm{OH}$-stearic, 9,10-di-OH-stearic (18) & $\begin{array}{l}0 \cdot 2-1 \cdot 0 \\
(\%, v / v)\end{array}$ & • & • & . \\
\hline $\begin{array}{l}\text { Unsaturated fatty acids : 14 pentadecenoic (15), } \\
\text { linoleic, linolenic, ricinoleic (18), erucic (22) }\end{array}$ & $\begin{array}{l}0 \cdot 2-2 \cdot 0 \\
(\%, w / v)\end{array}$ & $5 \cdot 0-8 \cdot 8$ & $2 \cdot 8-7 \cdot 4$ & $7 \cdot 0-10 \cdot 7$ \\
\hline Vaccenic (18) & $\begin{array}{l}0.2 \\
(\%, v / v)\end{array}$ & • & - & - \\
\hline $\begin{array}{l}\text { Esters of fatty acids: ethyl stearate, ethyl } \\
\text { oleate, methyl linoleate }\end{array}$ & $0 \cdot 25-2 \cdot 0$ & $5 \cdot 4-7 \cdot 3$ & $4 \cdot 9-8 \cdot 0$ & $7 \cdot 4-10 \cdot 5$ \\
\hline Glyceride: monoricinoleate & $\begin{array}{l}1 \cdot 0 \\
(\%, w / v)\end{array}$ & $7 \cdot 3$ & $5 \cdot 8$ & $10 \cdot 3$ \\
\hline $\begin{array}{l}\text { Sorbitan ester: polyoxyethylene oleate (Tween } \\
80 \text { ) }\end{array}$ & $0 \cdot 05-4 \cdot 0$ & $7 \cdot 0$ & $4 \cdot 0-7 \cdot 0$ & $9 \cdot 2$ \\
\hline
\end{tabular}

* Figures in parentheses refer to the number of carbon atoms in the preceding fatty acid.

Tables 4 and 5 show that the lipids which increased the yield of citric acid were natural oils high in unsaturated fatty acid, glycerides with at least one C18 unsaturated fatty acid and oleic acid itself. Natural oils with a high content of saturated fatty acids, saturated fatty acids and fatty acid esters were not effective. Of the C18 unsaturated fatty acids tested, only oleic acid (one double bond) was active; linoleic and linolenic acids (two and three double bonds, respectively) were not able to improve the yield of citric acid. In later experiments comparing oleic acid and peanut oil, oleic sometimes increased the citric acid yield as effectively as peanut oil, but more commonly peanut oil was superior.

In further experiments, natural oils which improved the yield of citric acid were treated in different ways and the treated oils tested. The yields of citric acid were estimated after 7 days. Peanut oil was dialysed for 4 days against medium $A$ and then used in a fermentation. Maize oil was fractionated (Hilditch, 1956) and the 
unsaponifiable fraction, glycerol and the mixed fatty acids from the saponifiable fraction were tested. Peanut oil samples were hydrogenated to give iodine numbers of 75 and 52 and these oils were compared in fermentations with the original peanut oil, iodine number 95. Peanut oil with iodine number 52 was added 24 hr. after inoculation, since germination of the spores was inhibited when this oil was added with the inoculum. The results of these fermentations are shown in Table 6, which shows that the activity of the oil lay in the saponifiable fraction, that no activity was lost with dialysis and that there was little loss in the ability of peanut oil to increase the citric acid yield until the iodine number had been decreased to $\mathbf{5 2}$.

Table 5. Lipids increasing citric acid yield by Aspergillus niger mutant 72-44

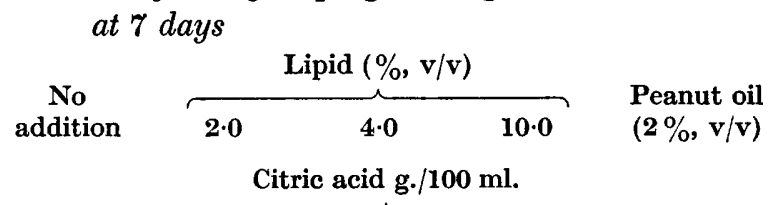

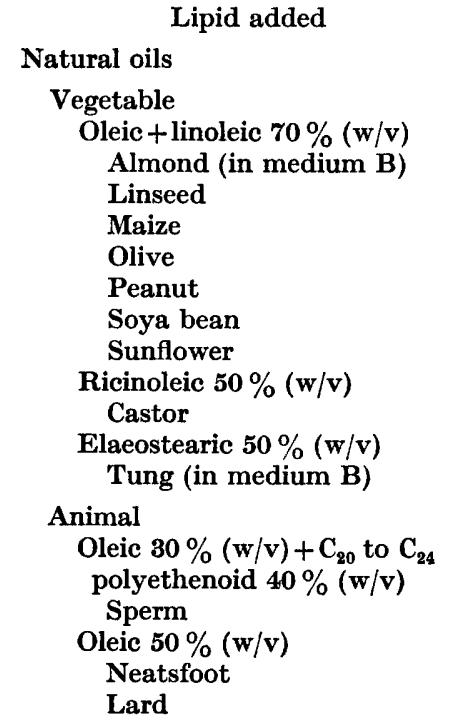

Glycerides

Distear

Triricinoleate

Monooleate

Trioleate

2 Oleate di-stearin

Monoglyceride of peanut oil (at 9 days)

$$
\begin{aligned}
& \mathbf{6 \cdot 6} \\
& 4 \cdot 6 \\
& 6 \cdot 5 \\
& 6 \cdot 2 \\
& 7 \cdot 0 \\
& 7 \cdot 0 \\
& \hline 7 \cdot 0 \\
& \hline 8 \cdot 7 \\
& \\
& \\
& \hline 7 \cdot 0 \\
& \hline 5 \cdot 0 \\
& 5 \cdot 0
\end{aligned}
$$



$\overbrace{0.5}^{\text {Lipid }(\%, \mathrm{v} / \mathrm{v})} \underbrace{(\% \cdot 0}_{\mathbf{1} \cdot 0}$

\section{$8 \cdot 4$}

$8 \cdot 5$

$6 \cdot 5$

8.0

\begin{tabular}{cc}
$\cdot$ & $10 \cdot 3$ \\
$8 \cdot 7$ & $10 \cdot 3$ \\
$8 \cdot 7$ & $10 \cdot 8$ \\
$\cdot$ & $10 \cdot 8$ \\
$11 \cdot 1$ & $10 \cdot 8$ \\
\hline & $11 \cdot 5$
\end{tabular}

Fatty acid

Unsaturated Oleic (18) 


\section{Effect of 2,4-dinitrophenol}

Several fatty acids including oleic acid are known to uncouple oxidative phosphorylation and to increase the respiration of isolated mammalian mitochondria (Pressman \& Lardy, 1956). Since oleic acid and natural oils high in oleic acid were the only lipids effective in increasing the citric acid yield, it seemed possible that these substances might be uncoupling the rate-controlling effect of phosphorylation in this fermentation. This would allow more rapid respiration and oxidation of reduced pyridine nucleotides and so increase citric acid production. The effect on citric acid yield of 2,4-dinitrophenol, a typical uncoupling reagent of oxidative phosphorylation, was therefore tested. 2,4-Dinitrophenol was added to a series of flasks at two concentrations on different days of the fermentation. The yields obtained after 7 days are shown in Table 7 , which shows that 2,4-dinitrophenol at $10^{-5} \mathrm{M}$ did not increase the yield of citric acid; at $10^{-4} \mathrm{M}$, the yield was decreased and growth inhibited.

Table 6. Effect of different treatments of maize and peanut oils on their ability to increase the yield of citric acid from Aspergillus niger mutant 72-44 at 7 days

Lipid added

No addition

Peanut oil dialysed 4 days

Peanut oil not dialysed

No addition

Maize oil

Unsaponifiable fraction of maize oil

Saponifiable fraction of maize oil

Glycerol

No addition

Peanut oil, iodine number 95

Peanut oil, iodine number 75

Peanut oil, iodine number 52 (added 24, hr. after inoculation)

\begin{tabular}{|c|c|}
\hline $\begin{array}{l}\text { Amount of lipid } \\
\qquad(\%, v / v)\end{array}$ & $\begin{array}{c}\text { Yield of } \\
\text { citric acid } \\
(\text { g. } / 100 \mathrm{ml} .)\end{array}$ \\
\hline . & $6 \cdot 5$ \\
\hline $2 \cdot 0$ & $8 \cdot 3$ \\
\hline $4 \cdot 0$ & $8 \cdot 3$ \\
\hline $10 \cdot 0$ & $7 \cdot 2$ \\
\hline $\mathbf{2 \cdot 0}$ & $8 \cdot 2$ \\
\hline . & $5 \cdot 8$ \\
\hline $1 \cdot 0$ & $7 \cdot 5$ \\
\hline $2 \cdot 0$ & $8 \cdot 0$ \\
\hline$(\%, w / v)$ & \\
\hline 0.02 & $6 \cdot 0$ \\
\hline $0 \cdot 1$ & $5 \cdot 8$ \\
\hline $0 \cdot 2$ & $5 \cdot 7$ \\
\hline$(\%, v / v)$ & \\
\hline 1.0 & $8 \cdot 3$ \\
\hline $2 \cdot 0$ & $8 \cdot 2$ \\
\hline 4.0 & $8 \cdot 5$ \\
\hline 1.0 & $6 \cdot 2$ \\
\hline . & $8 \cdot 2$ \\
\hline $2 \cdot 0$ & $11 \cdot 5$ \\
\hline $2 \cdot 0$ & $10 \cdot 7$ \\
\hline $2 \cdot 0$ & $8 \cdot 6$ \\
\hline
\end{tabular}

Effect of biotin. Since biotin is able to substitute as a growth factor for unsaturated fatty acids in some micro-organisms (Nieman, 1954) it was tested for its effect on citric acid accumulation. Over the range 0.2 to $40.0 \mu \mathrm{g}$. $/ 1$. it had no effect on yield.

\section{Amount of oil required and time of its addition}

Peanut, maize and olive oils each gave good yields of citric acid when added at the $2 \%(\mathrm{v} / \mathrm{v})$ in medium $\mathrm{A}$. Table 8 shows the results at 7 days following the addition of various amounts of oil. These results show that above $2 \%(v / v)$ there was no further 
marked improvement in yield. For subsequent work $2 \%(v / v)$ peanut oil was selected since peanut was the cheapest effective oil. In another experiment, $2 \%(\mathrm{v} / \mathrm{v})$ peanut oil was added on different days after inoculation and the citric acid determined after 7 days. It was shown that the oil could be added and give an increase in the citric acid yield either on the day of inoculation or $48 \mathrm{hr}$. after inoculation; added later than this it was ineffective.

Table 7. Effect of 2,4-dinitrophenol on citric acid yield by Aspergillus niger mutant 72-44 at 7 days

\begin{tabular}{|c|c|c|}
\hline Addition & $\begin{array}{c}\text { Day of } \\
\text { addition }\end{array}$ & $\begin{array}{c}\text { Yield of } \\
\text { citric acid } \\
\text { (g. } / 100 \mathrm{ml} \text {.) }\end{array}$ \\
\hline Nil & & 4.5 \\
\hline Peanut oil $2 \%, v / v$ & $\mathbf{0}$ & $8 \cdot 1$ \\
\hline 2,4-Dinitrophenol $10^{-5} \mathrm{M}$ & $\mathbf{0}$ & 4.8 \\
\hline $10^{-5} \mathrm{M}$ & 1 & $4 \cdot 3$ \\
\hline $1 \theta^{-5} \mathrm{M}$ & 2 & $4 \cdot 6$ \\
\hline $10^{-4} M$ & $\mathbf{2}$ & $\mathbf{2} \cdot 3$ \\
\hline $10^{-5} \mathrm{M}$ & $\mathbf{3}$ & $4 \cdot 8$ \\
\hline $10^{-5} \mathrm{M}$ & 4 & $4 \cdot 6$ \\
\hline
\end{tabular}

Table 8. Effect of different amounts of vegetable oils on the yield of citric acid with Aspergillus niger mutant 72-44 at 7 days

$\begin{array}{cccc}\begin{array}{c}\text { Amount of } \\ \text { oil added } \\ (\%, \mathrm{v} / \mathrm{v})\end{array} & \overbrace{\text { Maize }} \begin{array}{c}\text { Peanut } \\ \text { Citric acid (g./100 ml.) }\end{array} & \text { Olive } \\ 0 & \overbrace{}^{4 \cdot 6} & 7 \cdot 0 & \mathbf{5 \cdot 2} \\ 0 \cdot 1 & 6 \cdot 7 & - & 5 \cdot 7 \\ 0 \cdot 2 & 5 \cdot 7 & 7 \cdot 3 & 5 \cdot 2 \\ 0 \cdot 5 & 6 \cdot 8 & 9 \cdot 0 & 7 \cdot 0 \\ 1 \cdot 0 & 7 \cdot 5 & 9 \cdot 9 & 8 \cdot 5 \\ 2 \cdot 0 & 8 \cdot 1 & 9 \cdot 2 & 8 \cdot 5 \\ 3 \cdot 0 & 8 \cdot 0 & 9 \cdot 0 & 8 \cdot 4 \\ 4 \cdot 0 & 8 \cdot 5 & 10 \cdot 0 & - \\ 5 \cdot 0 & 9 \cdot 4 & & \end{array}$

The mycelial growth form was affected by the concentration of oil. In the absence of oil, the best yields of citric acid $(6-7 \mathrm{~g} . / 100 \mathrm{ml}$.) were associated with small fine pellets 1-2 mm. in diameter, while larger pellets 3-4 $\mathrm{mm}$. or porridge-like growth were associated with poor yields of $4 \mathrm{~g}$. citric acid/100 ml. In the presence of $2 \%$ $(\mathrm{v} / \mathrm{v})$ oil the pellets were about $1.0 \mathrm{~mm}$. in diameter, with the highest yields associated with pellets less than $1 \mathrm{~mm}$. in diameter in a fermentation mash of very low viscosity. In addition, at the end of fermentations which yielded $>9.5 \mathrm{~g}$. citric acid/ $100 \mathrm{ml}$. some of the oil remained free in the medium as firm oval pellets of about $4 \times 3 \mathrm{~mm}$. with the consistency of margarine.

\section{Utilization of oils}

Microscopic examination of the mycelium showed the oil to enter the hyphae within $24 \mathrm{hr}$. of its addition, where it was clearly defined in droplets. The amount of oil used by the mould was determined by adding a weighed amount of peanut oil to 
medium B in each of six flasks. The flasks were harvested after 7 days, pooled and the fermentation liquid, mycelium and solid oil pellets extracted with ether as outlined in Methods. The results are set out below:

$\begin{array}{lr} & \text { g. } \\ \text { Oil added } & \mathbf{6 \cdot 9 8} \\ \text { Oil recovered from: } & \\ \text { (1) mycelium } & \mathbf{0 \cdot 6 8} \\ \text { (2) fermentation liquid } & \mathbf{0 \cdot 0 7} \\ \text { (3) solid oil pellets } & \mathbf{0 \cdot 9 8} \\ \text { Total recovery } & \mathbf{1 \cdot 7 3} \\ \text { Recovery (\%) } & \mathbf{2 4 \cdot 8}\end{array}$

In this experiment, the addition of $2 \mathrm{~g}$. oil/100 ml. resulted in an increase in citric acid yield of $2 \mathrm{~g} . / 100 \mathrm{ml}$., with $25 \%$ of the oil recovered. Other experiments showed that oil caused no significant increase in dry weight of mycelium.

\section{Properties of the recovered oil}

As already indicated, the free oil which remained after fermentation was markedly changed in physical properties when the yield of citric acid had been increased by 1 to $3 \mathrm{~g} . / 100 \mathrm{ml}$. In experiments where the yield of citric acid was unaffected by added oil, the oil remained fluid to the end of the fermentation, indicating that the change in the physical properties was associated with its effect on citric acid yield. Changes in the melting point of oils can be caused by various changes in the fatty acids of the oil, for example, a change in chain length, the number, position or configuration of double bonds (Deuel, 1957). In addition, oxidation of the double bond to form epoxy acids can also decrease the iodine number. In an attempt to determine the changes which had occurred during fermentation, the iodine number of the peanut oil was determined by Hanus's method, before and after fermentation; it was found to be decreased from 95 to 72 in the recovered oil. This change might be due to saturation of double bonds or to other changes indicated above. The possibility that oxidation reactions were responsible for the decreased iodine number was tested by determining the peroxide values of the original and recovered oils as outlined in Methods.

The natural and recovered oils had similar peroxide values, indicating that the decreased iodine number was not due to oxidation reactions. Preliminary investigations by gas chromatography of the original and recovered oil indicated that the proportion of linoleic acid was decreased from 42 to 22 mole \% during fermentation, while stearic acid was increased from 3 to 9 mole \% and the oleic acid increased from 42 to 52 mole $\%$. It is clear, therefore, that the recovered peanut oil was considerably more saturated than the original oil. When the recovered oil was tested in a new fermentation, it no longer increased the yield of citric acid.

\section{Lipid as sole carbon source for citric acid production}

To determine whether peanut and maize oils could act as the sole source of carbon for acid production $2 \mathrm{ml}$. of oil were added to $50 \mathrm{ml}$. medium containing inorganic salts at the concentrations listed for medium $\mathbf{A}$ in Methods. These media were inoculated and incubated statically or shaken for 7 days. The dry weight of mycelium 
and the citric acid yield were then determined. The results are given in Table 9 , which shows that while these oils were adequate for growth, they did not replace sucrose for citric acid production.

Table 9. Oil as sole carbon source for citric acid production by Aspergillus niger mutant 72-44 at 7 days

\begin{tabular}{|c|c|c|c|}
\hline $\begin{array}{l}\text { Oil added } \\
(4 \%, v / v)\end{array}$ & $\begin{array}{l}\text { Growth } \\
\text { condition }\end{array}$ & $\begin{array}{c}\text { Dry wt. } \\
\text { mycelium } \\
\text { (g./100 ml.) }\end{array}$ & $\begin{array}{c}\text { Yield of } \\
\text { citric acid } \\
\text { (g. } / 100 \mathrm{ml} \text {.) }\end{array}$ \\
\hline Peanut & $\begin{array}{l}\text { Static } \\
\text { Shaken }\end{array}$ & $\begin{array}{l}0.5 \\
1.2\end{array}$ & $\begin{array}{l}0 \cdot 1 \\
0 \cdot 1\end{array}$ \\
\hline Maize & $\begin{array}{l}\text { Static } \\
\text { Shaken }\end{array}$ & $\begin{array}{l}0.5 \\
1.5\end{array}$ & $\begin{array}{l}0 \cdot 1 \\
0 \cdot 1\end{array}$ \\
\hline
\end{tabular}

\section{Purity of fermentation products}

Tests for the presence of organic acids other than citric were made as outlined in Methods. No acid other than citric was detected in any fermentation in the presence of the effective lipids peanut, maize, almond and tung oils, and oleic acid; nor in their absence.

\section{DISCUSSION}

Previous reports of substances which improved the yield of citric acid when added to fermentation media have shown these substances to be inhibitory to mould growth. In the present work on the effects of lipids on the yield of citric acid by Aspergillus niger mutant 72-44, the lipids which improved the yield were not inhibitory to growth; they could, in fact, act as the sole source of carbon for growth. There seem to be four possible ways in which lipids might act to increase the citric acid yield.

\section{(1) Physical effect}

The surface tension of liquids is altered by the addition of lipids, and it was formerly thought that, in fermentation media, lipids improved aeration efficiency. Deindoerfer \& Gaden (1955) showed, however, that lipids decrease oxygen transfer in media. In the present work it seems unlikely that the lipids which increased the yield of citric acid were doing so by virtue of any physical effect, since only a few of the lipids tested improved the yield of citric acid; and yet most of the lipids have similar physical effects.

\section{(2) Source of acetyl co-enzyme $A$}

It seemed possible that $\beta$-oxidation of the lipids could provide additional acetyl co-enzyme A (acetyl coA) for citric acid formation and so increase the yield. Peanut oil entered the mycelium of Aspergillus niger mutant 72-44 readily and only $25 \%$ of the added oil was recovered after fermentation, but the addition of lipid gave no increase in the dry weight of mycelium. It was possible then that the lipid was providing acetyl coA units for citric acid formation. However, saturated fatty acids like palmitic and stearic acids, oils with a high content of saturated fatty acids and the most highly hydrogenated peanut oil did not improve the yield of citric acid, and these lipids all provide acetyl $\operatorname{coA}$ units on $\beta$-oxidation. Although maize and peanut oils could act as the sole source of carbon for growth, they did not replace 
sucrose for citric acid production. Improved citric acid yields in the presence of lipid could be accounted for by improved sugar utilization. These findings do not support the hypothesis that the lipids acted as additional sources of acetyl coA in improving citric acid yields.

\section{(3) Hydrogen acceptor}

The only lipids active in this citric acid fermentation were oils with a high content of unsaturated fatty acids or the unsaturated oleic acid. The changes observed in the oils as a result of the fermentation indicated that hydrogenation of constituent unsaturated fatty acids occurred. This suggested that the unsaturated fatty acids were acting as alternative hydrogen acceptors to oxygen during fermentation, thus allowing the mould to metabolize actively for longer and so improving the yield of citric acid. The importance of oxygen in all mould submerged culture fermentations has been stressed repeatedly (Finn, 1954; Arnold \& Steel, 1958). When Shu (1953) used pure oxygen instead of air in a citric acid fermentation he obtained an increased citric acid yield.

Several observations in the present work support the theory that the effective lipids act as hydrogen acceptors. No saturated fatty acid or oils high in saturated fatty acids were effective. In fermentations with partially hydrogenated peanut oils, peanut oil with an iodine number of 52 gave no increase in yield, but oil with an iodine number of 75 was almost as active as the natural peanut oil (see Table 6). Hilditch (1947) showed that when peanut oil was hydrogenated, the component fatty acids were hydrogenated in a definite order, governed by the number and arrangement of the double bonds in the fatty acids. He found that in decreasing the iodine number from $93 \cdot 3$ to $71 \cdot 6$, the linoleate content was decreased from 26 to $3 \%$ and that the oleate content rose from 56 to $77 \%$. In the present work, then, it seems probable that the peanut oil with an iodine number of 75 had a high content of oleic acid and gave a large increase in yield, and that it was not until the iodine number was decreased to $\mathbf{5 2}$ that the oleic acid content was so diminished that the oil was no longer active.

The hydrogen acceptor theory explains why saturated fatty acids and oils high in saturated fatty acids did not improve the citric acid yield and why oleic acid was effective. On this theory, however, it might be expected that linoleic and linolenic acids would also improve yield, but this was not found to be so. Their failure may have been due to steric differences caused by the larger number of double bonds in these two acids.

Trumpy \& Millis (1963) found that when $\mathrm{NH}_{4} \mathrm{NO}_{3}$ was present at $2 \cdot 7 \mathrm{~g}$. $/ 1$. then peanut oil did not improve the yield of citric acid, but at concentrations less than $2.7 \mathrm{~g}$./l. addition of oil increased the yield. The dry weight of mycelium remained unchanged at all concentrations of $\mathrm{NH}_{4} \mathrm{NO}_{3}$ in the presence or absence of oil. This observation is difficult to reconcile with the hydrogen acceptor theory unless it is postulated that at higher concentrations of $\mathrm{NH}_{4} \mathrm{NO}_{3}$, the nitrate also acts as an alternative hydrogen acceptor, oil then being ineffective.

\section{(4) Uncoupling of oxidative phosphorylation}

In the citric acid fermentation one of the factors which improves the yield of acid is a low phosphate content in the medium. This leads to low concentrations of 
adenosine diphosphate (ADP) and inorganic phosphate in the mycelium. Although growth in a high-yielding citric acid fermentation is limited, the conversion of sugar to citric acid proceeds rapidly. The rate of respiration would be increased if the ratecontrolling effect of phosphorylation were uncoupled from respiration. In many cells the concentrations of inorganic phosphate and ADP govern the rate of respiration and thus the rate of oxidation of the reduced pyridine nucleotides and citric acid formation. Scholefield (1956) found that octanoic and decanoic acids were active as uncoupling reagents. Pressman \& Lardy (1956) found that myristic acid and the unsaturated fatty acids with cis bonds, oleic, linoleic and linolenic acids, were also active as uncoupling reagents in mitochondrial preparations. It seemed possible therefore that in the citric fermentation by Aspergillus niger, the lipids might act by uncoupling respiration from phosphorylation. This would result in a faster rate of respiration and an improvement in citric acid accumulation. While this theory explains the activity of oleic acid, it cannot explain why linoleic, linolenic, myristic, octanoic and decanoic acids, which are also active uncoupling reagents, did not increase citric acid yield by $\boldsymbol{A}$. niger. Similarly 2,4-dinitrophenol did not improve citric acid yield though it too is an active uncoupling reagent. It is always possible that the intact mycelium was impermeable to the ineffective reagents. This does not seem probable since 2,4-dinitrophenol at $10^{-4} \mathrm{M}$ and saturated fatty acids with less than 13 carbon atoms all inhibited growth and must therefore have entered the mycelium.

Of the possible explanations of the mode of action of lipids in the citric acid fermentation by Aspergillus niger, it seems that the hydrogen acceptor theory is the one to which fewest objections can be raised. More definitive experiments need to be done with cell-free systems to determine whether or not unsaturated lipids can act as hydrogen acceptors and, if so, how specific the reaction is with respect to the structure of the acceptor fatty acid. The addition of appropriate lipids to the fermentation medium offers a considerable advantage for citric acid production on an industrial seale. This study, and others to be published, have shown that lipids improve the citric acid yield by $\mathbf{2 0 - 5 0} \%$ in a wide variety of media. Lipids do not eliminate variability in yield, but the lowest yields in the presence of lipid are increased considerably compared with the lowest yields in the absence of lipid. In addition, in aerated and stirred fermentations lipids act as effective antifoam agents. The addition of lipids to fermentation media for citric acid production is the subject of a patent application by the University of Melbourne (1960).

We are indebted to Mr N. Weichman (Marrickville Margarine Pty Ltd, N.S.W.) for giving us 10 gallons of peanut oil and other lipids and for the analyses by gas chromatography of samples of peanut oil. We are also indebted to the Standard Defence Laboratories, Melbourne, Spartan Paint Co., Melbourne, and the Biochemistry Departments of Sydney and Melbourne Universities for gifts of lipids. The technical assistance of Mr M. Grinbergs and Mr R. Bearlin is gratefully acknowledged. Grants from the National Health and Medical Research Council of Australia and the University of Melbourne Research Fund provided financial support for two of us (B.H.T.; B.M.P.). 


\section{REFERENCES}

Arnold, B. H. \& Steel, R. (1958). Oxygen supply and demand in aerobic fermentations. In Biochemical Engineering, p. 149. Ed. R. Steel. London: Heywood and Co. Ltd.

Bernhauer, K. (1929). Über die Charakterisierung der Stämme von Aspergillus niger. II. Mitteilung: Die Bedeutung saurer Substrate für die Charakterisierung und Züchtung der Pilzstämme. Biochem. Z. 205, 240.

Bernhauer, K., KNobloch, H. \& Iglauer, A. (1941). U̇ber die Säurebildung aus Zucker durch Aspergillus niger. XI. Mitteilung: Faktoren der Citronensäureanhäufung 2. Biochem. Z. 309, 151.

Bernhauer, K., Rauch, J. \& Gross, G. (1949). Ủber die Säurebildung aus Zucker durch Aspergillus niger. XIII. Mitteilung: Die Citronensäurebildung aus Zuckerrubenmelasse in der Oberflächenkultur. Biochem. Z. 319, 499.

Cooper, C. M., Fernstrom, G. A. \& Miluer, S. A. (1944). Performance of agitated gasliquid contactors. Ind. Engng Chem. 36, 504.

Deindoerfer, F. H. \& Gaden, E. L., Jr. (1955). Effect of liquid physical properties on oxygen transfer in penicillin fermentations. $J$. appl. Microbiol. 3, 253.

Deuer, H. J., Jr. (1957). The Lipids. Their Chemistry and Biochemistry, vol. I. Chemistry, p. 52. New York, London: Interscience Publishers Inc.

Doelger, W. P. \& Prescott, S. C. (1934). Citric acid fermentation. Ind. Engng Chem. 26, 1142.

Feigl, F. (1960). Spot Tests in Organic Analysis, p. 385, 6th ed. London: Elsevier Pub. Co.

Finn, R. K. (1954). Agitation-aeration in the laboratory and in industry. Bact. Rev. 18, 254.

Foster, J. W. (1949). Chemical Activities of Fungi. New York: Academic Press, Inc.

Gardner, J. F., James, L. V. \& Rubbo, S. D. (1956). Production of citric acid by mutants of Aspergillus niger. J. gen. Microbiol. 14, 228.

Gerhardt, P., Dorrell, W. W. \& Baldwin, I. L. (1946). Citric acid fermentation of beet molasses. J. Bact. 52, 555.

Hilditch, T. D. (1947). J. Oil Col. Chem. Assoc. 30, 1, cited by Gunstone, F. D. (1958). In An Introduction to the Chemistry of Fats and Fatty Acids. London: Chapman and Hall Ltd.

Hilditch, T. D. (1956). The Chemical Constitution of Natural Fats, 3rd ed. London: Chapman and Hall Ltd.

JACOBs, M. B. (1958). The Chemical Analysis of Foods and Food Products, p. 393. Princeton, New Jersey: D. Van Nostrand Company Inc.

James, L. V., Rubbo, S. D. \& Gardner, J. F. (1956). Isolation of high acid yielding mutants of Aspergillus niger by a paper culture selection technique. J. gen. Microbiol. 14, 223.

Johnson, M. J. (1954). The citric acid fermentation. In Industrial Fermentations, vol. I. Ed. by L. A. Underkofler \& R. J. Hickey. New York: Chemical Pub. Co., Inc.

MARIER, J. R. \& Boulet, M. (1958). Direct determination of citric acid in milk with an improved pyridine-acetic anhydride method. J. Dairy Sci. 41, 1683.

Martin, S. M. \& Waters, W. R. (1952). Production of citric acid by submerged fermentation. Ind. Engng Chem. 44, 2229.

Moyer, A. J. (1953). Effect of alcohols on the mycological production of citric acid in surface and submerged culture. (i) The nature of the alcohol effect. J. appl. Microbiol. 1,1 .

Nieman, C. (1954). Influence of trace amounts of fatty acids on the growth of microorganisms. Bact. Rev. 18, 147.

Official Methods of Analysis of the Association of Official Agricultural Chemists (1955). 8th ed. Washington, A.O.A.C.

Perlman, D. (1943). Factors affecting the production of citric acid by Aspergillus niger. M.S. thesis, University of Wisconsin, cited by ShU, P. \& Johnson, M. J. (1948b).

Perlman, D., Kita, D. A. \& Peterson, W. H. (1946). Production of citric acid from cane molasses. Arch. Biochem. 11, 123. 
Perlman, D. \& Sin, C. J. (1960). Fungal synthesis of citric, fumaric and itaconic acids. Prog. ind. Microbiol. 2, 168.

Pressman, B. C. \& Lardy, H. A. (1956). Effects of surface active agents on the latent ATPase of mitochondria. Biochim. biophys. Acta, 21, 458 .

Scholefield, P. G. (1956). Studies of fatty acid oxidation. The effects of fatty acids on the oxidation of other metabolites. Canad. J. Biochem. 34, 1227.

Schaffer, P. A. \& Somogyi, M. (1933). Copper-iodometric reagents for sugar determinations. J. biol. Chem. 100, 695.

Shu, P. \& Johnson, M. J. (1947). Effect of the composition of the sporulation medium on citric acid production by Aspergillus niger in submerged culture. J. Bact. 54, 161.

Shu, P. \& Johnson, M. J. (1948a). Citric acid production by submerged fermentation with Aspergillus niger. Ind. Engng Chem. 40, 1202.

Shu, P. \& Johnson, M. J. (1948b). The interdependence of medium constituents in citric acid production by submerged fermentation. J. Bact. 56, 577 .

Shu, P. (1953). Oxygen uptake in shaken flask fermentations. J. Agric. Fd Chem. 1, 1119.

SмIтн, I. (1962). Chromatographic and Electrophoretic Techniques. 2nd ed., vol. I. Chromatography, p. 83. New York: Interscience Pub., Inc.; London: William Heinemann Medical Books Ltd.

Trumpy, B. H. \& Millis, N. F. (1963). Nutritional requirements of an Aspergillus niger mutant for citric acid production. J. gen. Microbiol. 30, 381.

University of Melbourne (1960). Production of citric acid. Aust. Pat. Application No. $58,946 / 60$. 